\title{
A review of ocular perfusion pressure and retinal thickness: A case for the role of systemic hypotension in glaucoma
}

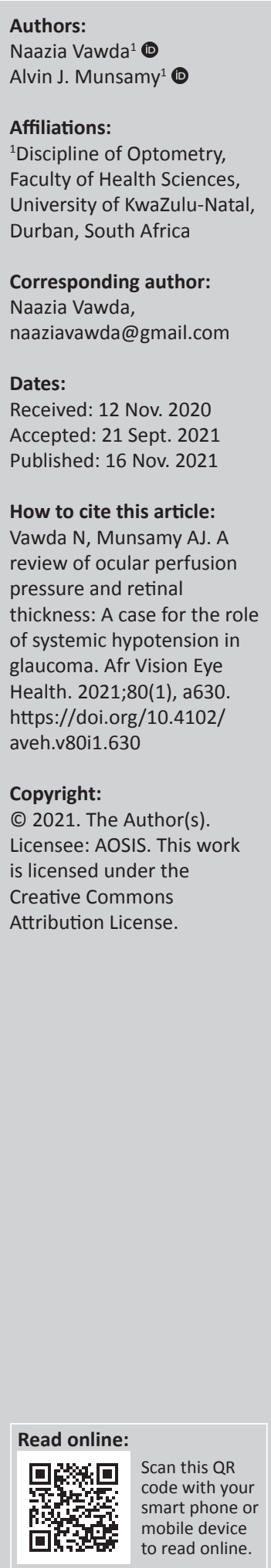

Background: Ocular perfusion pressure (OPP) is defined as blood pressure (BP) minus intraocular pressure (IOP). Low OPP may result in decreased ocular blood flow (OBF) and oxygen to the optic nerve head $(\mathrm{ONH})$ and retina.

Aim: To review the role of systemic hypotension and similar conditions in OPP and its influence on retinal nerve fibre layer (RNFL) thickness and the ganglion cell complex (GCC).

Method: A literature search was conducted using the following search terms: 'systemic hypotension'; 'glaucoma'; 'retinal nerve fibre layer'; 'optic nerve'; 'ocular blood flow' and 'ocular perfusion pressure'.

Results: The Los Angeles Eye Study and Barbados Eye Study found that decreased OPP and $\mathrm{BP}$ increased the risk of glaucoma development by up to six times. Reduced retinal perfusion with resultant thinning of the RNFL in conditions with a similar mechanism, such as obstructive sleep apnoea syndrome, has indicated the importance of reduced OPP in retinal thickness. In the absence of any study directly showing the effect of systemic hypotension on OPP and retinal thickness, a working hypothesis proposes that reduced BP with or without normalto-raised IOP will reduce OPP. The reduced OPP and OBF in those with systemic hypotension may result in oxidative stress and hypoxia which may then cause retinal ganglion cell death and the resultant retinal thinning.

Conclusion: The increased risk of glaucoma development and progression relating to decreased BP and OPP has been proven to be of importance. Monitoring patients with systemic hypotension and evaluating the macula, ONH RNFL and GCC thickness may alert clinicians to possible glaucomatous changes.

Keywords: ocular perfusion pressure; blood pressure; intraocular pressure; retinal nerve fibre layer; ganglion cell complex.

\section{Background}

Ocular perfusion pressure (OPP) is defined as the difference between arterial blood pressure (BP) entering the eye and intraocular pressure (IOP). ${ }^{1}$ Low OPP occurs as a result of low BP and/or high IOP, with IOP being equal to retinal venous pressure. ${ }^{2}$ The vascular theory states that, in the event of low BP, there is a subsequent decrease in OPP, resulting in less ocular blood flow (OBF) and oxygen to the optic nerve head $(\mathrm{ONH}){ }^{3}$ Structural damage and low OPP constitute a secondary element in OBF reduction. ${ }^{2}$ Wang et al. ${ }^{1}$ reduced OPP by varying BP and IOP in animal studies to assess the susceptibility of ONH autoregulation blood flow. This showed that $\mathrm{ONH}$ blood flow was significantly affected by a decrease in OPP as a result of lowered BP, in comparison to increased IOP.

The vulnerability of ONH blood flow to lowered BP provides an insight into the pathophysiology of glaucoma. The OBF is highly regulated by an autoregulation mechanism to adjust to changing visual function and subsequent changing metabolic needs. Autoregulation compensates for changes in OPP and maintaining the temperature at the back of the eye. A physiological or pathological fluctuation in OPP leads to a paralleled fluctuation of OBF. ${ }^{4}$ An impaired autoregulation capacity contributes to the initiation and/or progression of glaucomatous optic neuropathy and this indicates that the ONH can no longer compensate for the fluctuations in OPP. ${ }^{1}$

Systemic conditions that result in reduced BP, such as systemic hypotension, may consequently affect OPP. This review attempts to show the effect of reduced systemic BP on OPP and its resultant 
effect on the retinal nerve fibre layer (RNFL) and ganglion cell complex (GCC) thickness. Decreased OPP may result in reduced $\mathrm{OBF}$ and hypoxemia to retinal structures.

\section{Methods}

The literature search was performed using Google Scholar, PubMed and Science Direct databases, using the search terms 'systemic hypotension', 'glaucoma', 'retinal nerve fibre layer', 'optic nerve', 'ocular blood flow' and 'ocular perfusion pressure'. Articles relating to OPP and retinal thinning which were associated with systemic hypotension or conditions with a similar mechanism of reduced ocular perfusion were included in this review.

\section{Intraocular pressure}

Intraocular pressure has been known to be a risk factor for the development and progression of glaucoma. ${ }^{5}$ Intraocular pressure is subject to chrono-biological rhythms and these fluctuations may be because of physiological factors which have been recognised as clinically important, because they can directly affect the management and diagnosis under IOPrelated conditions. ${ }^{6}$ The reported mean amplitude of daily IOP fluctuation ranges between 3 millimetre of mercury $(\mathrm{mmHg})$ to $6 \mathrm{mmHg}$ and with a peak IOP in the morning hours. ${ }^{7}$ Twenty-four-hour phasing is the most accurate method of determining IOP curves. However, this has proven to be expensive and impractical. ${ }^{5}$

A study by Dinn et al., ${ }^{8}$ on the concordance of IOP between fellow eyes in primary open-angle glaucoma (POAG) participants, found that the IOP may fluctuate occasionally. The absolute change of IOP between fellow eyes was $2 \mathrm{mmHg}$ for $68 \%$ to $90 \%$ and $3 \mathrm{mmHg}$ for $78 \%$ to $95 \%$. A study by Shuba et al. ${ }^{9}$ found the diurnal variation between the right and left eyes in glaucoma suspects, and normaltension glaucoma (NTG) participants, to be concordant approximately $90 \%$ of the time. Bhorade et al. ${ }^{10}$ measured IOP in untreated ocular hypertensive participants with no evidence of glaucoma over 60 months. The study found a high correlation between IOP measurements in the right and left eyes, regardless of the time of the day. The study also found a higher correlation between fellow eyes at the same visit, as compared to different visits, suggesting that factors that influence IOP are more concordant at the same visit and that there may be no significant difference between eyes.

A study by David et al. ${ }^{6}$ on 690 diurnal IOP curves found $41 \%$ of overall IOP peaks in the first, earliest measurement taken from 7:45 to 9:00. Kim et al. ${ }^{11}$ studied BP and IOP in NTG patients with undisturbed sleep and found that $50 \%$ of NTG patients experienced an IOP peak at 7:00. The mean IOP peak in the control group and the NTG group was highest in the early parts of the morning. Sajja et al. ${ }^{7}$ studied 100 healthy participants between 20 years and 60 years old, and found peak IOP readings in the morning (9:00-10:00) and troughs in the afternoon (15:00-16:00).

Supine IOP studied by Liu et al. ${ }^{12}$ confirmed that nocturnal supine IOP was higher than diurnal seated IOP in individuals with healthy eyes. The study also found that, in untreated glaucoma patients, nocturnal supine IOP was also higher than diurnal sitting IOP. The main factors influencing the nocturnal IOP elevation may be the shift from a daytime upright posture to a supine posture at night. ${ }^{7}$ Kotecha et al. ${ }^{13}$ also suggested in their study of the relationship between diurnal IOP and corneal thickness that the peak in measured IOP during the early morning may be explained in part by the effects of a hydration-related corneal thickness increase, induced by overnight eye closure.

Table 1 provides a summary of IOP patterns with regard to diurnal influence, as well as the concordance of IOP between eyes in glaucomatous and non-glaucomatous eyes.

Variables that influence IOP measurement include body position, water consumption, time of the day and stress. The IOP is lowest when the patient is sitting in a neutral position; and bending or tilting the head or neck can affect results. Water consumption increases the venous pressure and may result in IOP increasing by up to $6 \mathrm{mmHg}$. Increased stress levels cause hormonal changes resulting in changes in IOP, whilst pain or squeezing of the eyes may also affect measurements. ${ }^{15}$ In addition, IOP has been found to peak at night in two-thirds of patients. ${ }^{15}$

The OPP can vary, either with high IOP or low BP. ${ }^{2}$ Low OPP can also occur when IOP is normal and only BP is low. ${ }^{16}$ Because IOP is within a normal range, this is related to NTG. ${ }^{2}$

TABLE 1: Intraocular pressure patterns of behaviour in glaucomatous and non-glaucomatous eyes.

\begin{tabular}{|c|c|c|c|c|c|}
\hline Study (year) & $n$ & Population type & IOP & Peak & Trough \\
\hline \multicolumn{6}{|c|}{ Concordance between eyes } \\
\hline Dinn et al. $(2007)^{8}$ & 93 & POAG & $\begin{array}{l}\text { The absolute change of IOP between fellow eyes was } \\
2 \mathrm{mmHg} \text { for } 68 \% \text { to } 90 \% \text { and } 3 \mathrm{mmHg} \text { for } 78 \% \text { to } 95 \% \text {. }\end{array}$ & - & - \\
\hline Shuba et al. $(2007)^{9}$ & 163 & NTG/Glaucoma suspects & Concordant approximately $90 \%$ of the time & - & - \\
\hline Bhorade et al. $(2009)^{10}$ & 810 & Untreated ocular hypertension & No significant difference between eyes & - & - \\
\hline \multicolumn{6}{|l|}{ Peak and trough of IOP } \\
\hline Kim et al. $(2011)^{14}$ & 102 & Non-glaucomatous & - & $9: 00$ & $15: 00$ \\
\hline Sajja et al. $(2013)^{7}$ & 100 & Normal & - & 9:00-10:00 & $15: 00-16: 00$ \\
\hline
\end{tabular}

IOP, intraocular pressure; POAG, primary open-angle glaucoma; NTG, normal-tension glaucoma; $\mathrm{mmHg}$, millimetre of mercury. 
The OPP becomes a dynamic factor because IOP and BP peak and trough throughout the day. The OPP is more sensitive to $\mathrm{BP}$ changes than IOP changes, because $\mathrm{BP}$ varies in the range of $40 \mathrm{mmHg}$ to $60 \mathrm{mmHg}$ and IOP varies in the range of $5 \mathrm{mmHg}$ to $8 \mathrm{mmHg} .{ }^{17}$ The Los Angeles Latino Eye Study ${ }^{18}$ found a median of $17 \mathrm{mmHg}$, with only $18 \%$ of glaucoma participants with IOP greater than $21 \mathrm{mmHg}$. Similarly, the median IOP was $20 \mathrm{mmHg}$ in the Baltimore Eye Survey ${ }^{19}$ with $41 \%$ of all eyes with an IOP of greater than $21 \mathrm{mmHg}$. Therefore, we cannot entirely attribute IOPs greater than $21 \mathrm{mmHg}$ to this increased risk for glaucoma. ${ }^{20}$ Variations in IOP during the day, with regard to peaks in the morning and troughs in the afternoon, may result in changes in OPP. Other factors such as stress, water consumption and body position also have an influence on IOP, ultimately affecting OPP.

\section{Systemic hypotension: A case for ocular perfusion pressure Background}

Optimal in-office BP levels have been defined as less than $120 \mathrm{mmHg}$ systolic BP and less than $80 \mathrm{mmHg}$ diastolic BP. ${ }^{21}$ The World Health Organization (WHO) ${ }^{22}$ defined systemic hypotension as systolic blood pressure (SBP) lower than $100 \mathrm{mmHg}$ in women and $110 \mathrm{mmHg}$ in men, regardless of diastolic blood pressure (DBP). The Los Angeles Latino Eye Study ${ }^{18}$ defined hypotension as SBP $\leq 90$ $\mathrm{mmHg}$ and $\mathrm{DBP} \leq 60 \mathrm{mmHg}$. There are two known forms of systemic hypotension: primary hypotension which includes essential and constitutional hypotension, and secondary hypotension. ${ }^{23}$ Primary or constitutional hypotension refers to chronically reduced BP, independent of any pathological factors. ${ }^{24}$ Secondary hypotension differs as it may be as a result of blood loss, orthostatic hypotension or medication..$^{23}$ Constitutional hypotension is relatively widespread and is not commonly regarded as a threat. However, it has been found to have a significant impact on personal well-being and quality of life, as shown in several epidemiological studies. ${ }^{24}$ The aetiology of hypotension includes reduced liquid intake and low body weight; and dysregulation of the autonomic nervous system may be of significance. ${ }^{24}$ The United States National Centre for Health Statistics ${ }^{25}$ defines chronic disease as a condition lasting three months or longer. Despite systemic hypotension not being treated as acutely as hypertension, it may present in sufferers for longer than three months and may be regarded as a chronic condition.

Based on clinical BP measurements, it is estimated that symptoms develop in systemic hypotension at $<75 \mathrm{mmHg}^{26}$ $\mathrm{DBP}$ and $\leq 115 \mathrm{mmHg}^{27}$ and $<118 \mathrm{mmHg}^{28} \mathrm{SBP}$ in males; and $48.9 \mathrm{mmHg}$ DBP and $\leq 109 \mathrm{mmHg}^{27}$ and $<100 \mathrm{mmHg}^{29} \mathrm{SBP}$ in females. Chronic hypotension is a poorly understood concept and there is a scarcity of scientific work on the subject.

\section{Factors influencing clinical measurements}

Several factors have been found to influence BP readings, such as diurnal effects, cuff size, posture and arm position, clothing, temperature and alcohol, caffeine and smoking intake. Degaute et al. ${ }^{30}$ found that BP peaks at mid-morning (10:00 am) and declines towards late afternoon (15:00). Similarly, Koroboki et al. ${ }^{31}$ found that BP in normotensives peaks at around 10:00 and troughs at around 16:00. Handler ${ }^{32}$ found that the cuff being the incorrect size may cause a variation of approximately $10 \mathrm{mmHg}-40 \mathrm{mmHg}$, and if the cuff is placed over clothing, this may cause an increase or decrease in variation by $10 \mathrm{mmHg}-50 \mathrm{mmHg}$. The back being unsupported may cause the DBP to increase by 6 $\mathrm{mmHg}$ and if the feet are crossed, this may also increase SBP by $2 \mathrm{mmHg}$ to $8 \mathrm{mmHg}$. The arm is required to be at heart level, and BP may increase or decrease by $2 \mathrm{mmHg}$ if the arm is above or below heart level, respectively. Smoking should be avoided for $30 \mathrm{~min}$ before the reading is taken as it can cause an increase in variation from $5 \mathrm{mmHg}$ to $8 \mathrm{mmHg}$. A full bladder can increase SBP by $10 \mathrm{mmHg}-15 \mathrm{mmHg} .{ }^{32}$ Pickering et al. ${ }^{33}$ found that not resting for 3-5 min, or increased stress levels because of the emotional state of the patient, may cause a variation of up to $40 \mathrm{mmHg}$. Cold temperatures also cause BP to increase. Alcohol and caffeine should be avoided $30 \mathrm{~min}$ before readings are taken and can increase readings by $5 \mathrm{mmHg}-8 \mathrm{mmHg}$. Even talking has been shown to increase systolic pressure by $10 \mathrm{mmHg}-$ 15 mmHg. ${ }^{33}$

\section{Gender influences}

Wessely et al. ${ }^{34}$ studied the symptoms of low BP and concluded that systemic hypotension is associated with persistent tiredness and feeling faint. A distinct relationship between SBP and tiredness in both men and women was found. In men, the trend was present only for lower SBPs; but in women, it was present throughout the range. Fainting and dizziness were significant in the youngest and the oldest participants, and showed a U-shaped curve. Low BP and both tiredness and feeling faint were most pronounced in the younger age group.

Rosengren et al..$^{28}$ studied the effect of hypotension on selfperceived well-being on middle-aged men. A significant relationship was found between low systolic and DBP and impaired social, physical and mental well-being. Mental variables such as energy and patience were also significant with regard to reduced BP. In 1989, Pemberton ${ }^{35}$ used Australian data to analyse symptoms of heart palpitations, dizziness, fainting and tiredness in relation to BP. A significant association was found between low BP and tiredness in women. Pemberton also found hypotension to be prevalent in $3.6 \%$ of females. In a study by Pilgrim et al., ${ }^{27}$ dizziness and giddiness in men and unexplained tiredness in both men and women were significantly related to low SBP.

In a longitudinal study of the basic characteristics of hypotension, Akahoshi et al. ${ }^{36}$ found females to be predominant in their sample at $1 \%$ in comparison to males at $0.2 \%$. The study measured several characteristics associated with chronic hypotension, namely anthropometric index (body mass index [BMI]), heart rate and body temperature, 
haemoglobin and biochemistry. When BMI was adjusted for a low heart rate, creatinine, body temperature and haemoglobin were significantly lowered in hypotensive patients, indicating a lowered sympathetic nervous system in hypotension. The study also found lower BMI values, which indicate that chronic hypotension cases occur in individuals with small build/slender body types, or who have small muscle mass.

The basic characteristics of hypotension indicate that chronic hypotensive patients are predominantly females with low BMI. This indicates a lower sympathetic nervous system and small body mass, in addition to low SBP which does not increase with age, ${ }^{36}$ thus highlighting gender vulnerabilities in systemic hypotension and the possibility of OPP influences, which may set them at a greater risk for glaucomatous optic neuropathy.

\section{Clinical significance of ocular perfusion}

Low OPP is a risk factor for glaucoma. Table 2 shows landmark studies that explored the relationship between OPP and glaucoma. The Los Angeles Latino Eye Study ${ }^{18}$ found that participants with DBP $\leq 60 \mathrm{mmHg}$, SBP $>160 \mathrm{mmHg}$, mean OPP (MOPP) $\leq 50 \mathrm{mmHg}$, diastolic OPP $($ DOPP) $\leq 40 \mathrm{mmHg}$ and systolic OPP (SOPP) $\leq 80$ $\mathrm{mmHg}$, were all associated with a higher prevalence of open-angle glaucoma (OAG). The Barbados Eye Study ${ }^{37}$ found that the incidence of OAG was highest with low OPP. Those with low SOPP $(<101.3 \mathrm{mmHg})$ were at a 2.6 times higher risk; low DOPP $(<55 \mathrm{mmHg})$ indicated a 3.2 times higher risk and low MOPP $(<42 \mathrm{mmHg})$ indicated a 3.1 times higher risk of developing OAG. The Baltimore Eye Survey ${ }^{19}$ found that those with DOPP $<30 \mathrm{mmHg}$ had a six times higher risk of developing POAG when compared to those with DOPP > $50 \mathrm{mmHg}$. The Early Manifest Glaucoma Trial ${ }^{38}$ evaluated BP reduction in patients with normal IOP and early glaucoma and found that those with SBP $<60 \mathrm{mmHg}$ were at higher risk of progression. The Proyecto VER ${ }^{39}$ studied the prevalence of glaucoma in Hispanics over 40 years of age. Diastolic OPP was calculated and it was found that those with DOPP < $50 \mathrm{mmHg}$ were at a four times higher risk of OAG. The Egna-Neumarkt Study ${ }^{40}$ assessed the impact of vascular factors on the prevalence of OAG. Lower DOPP was associated with a significant and progressive increase in the frequency of hypertensive glaucoma. The study found that those with DOPP $<68 \mathrm{mmHg}$ were at a 2.5 times higher risk of OAG. The Singapore Malay Eye Study ${ }^{41}$ (2010) studied the relationship between OPP and OAG and found that individuals with low DBP, MOPP $<46$ $\mathrm{mmHg}$ and DOPP $<54 \mathrm{mmHg}$, were all at a higher risk of OAG. Choi et al. ${ }^{42}$ found that MOPP was the most consistent clinical risk factor for NTG and that average RNFL thickness was significantly related to mean arterial pressure (MAP) and MOPP fluctuation.

Low OPP in normal patients, and those with early glaucoma and hypertension have been shown to increase the risk of glaucoma by up to six times in some cases. Low BP has also been found to contribute to the increased risk of progression, thus making the assessment of hypotension in relation to OPP vital in monitoring the risk of glaucoma development and progression.

Reduced OPP results in a loss of retinal ganglion cells (RGCs) as a consequence of primary and secondary insult. ${ }^{43}$ Primarily, low OPP causes reduced ONH blood flow with the reduced flow of nutrients to the RGC axons, resulting in $\mathrm{ONH}$ ischemia. Furthermore, OPP fluctuation can cause ischemia-reperfusion damage to ganglion cells by oxygen free radicals and nitric oxide species. ${ }^{44}$ Secondary insult because of reduced OPP may occur because of abnormal autoregulation. If OPP falls below the lower autoregulatory limit, RGC's function at lower energy levels is more susceptible to ischemia. ${ }^{43}$

TABLE 2: Ocular perfusion pressure and blood pressure and their association with glaucoma.

\begin{tabular}{|c|c|c|c|c|}
\hline Study (year) & $N$ & OPP/BP & OPP/BP & Association with glaucoma \\
\hline Los Angeles Latino Eye Study $(2010)^{18}$ & $\begin{array}{l}287 \\
5843\end{array}$ & $\begin{array}{l}\text { OAG } \\
\text { No OAG }\end{array}$ & $\begin{array}{l}\text { MOPP } \leq 50 \mathrm{mmHg} \\
\text { DOPP } \leq 40 \mathrm{mmHg} \\
S O P P \leq 80 \mathrm{mmHg} \\
\text { DBP } \leq 60 \mathrm{mmHg}\end{array}$ & 4 times higher risk of OAG. \\
\hline Barbados Eye Study $(2002)^{37}$ & 2989 & At risk for OAG & $\begin{array}{l}\text { SOPP }<101.3 \mathrm{mmHg} \\
\text { DOPP }<55 \mathrm{mmHg} \\
\text { MOPP }<42 \mathrm{mmHg}\end{array}$ & $\begin{array}{l}\text { 2.6 times higher risk of OAG } \\
\text { 3.2 times higher risk of OAG } \\
\text { 3.1 times higher risk of OAG }\end{array}$ \\
\hline Baltimore Eye Study $(1995)^{19}$ & $\begin{array}{l}161 \\
5147\end{array}$ & $\begin{array}{l}\text { POAG } \\
\text { No POAG }\end{array}$ & $\mathrm{DOPP}<30 \mathrm{mmHg}$ & 6 times higher risk of OAG \\
\hline The Early Manifest Glaucoma Trial (1999) ${ }^{38}$ & 255 & Early glaucoma & $\mathrm{SBP}<60 \mathrm{mmHg}$ & Higher risk of progression \\
\hline Egna-Neumarkt Study $(2000)^{40}$ & $\begin{array}{l}4087 \\
89 \\
60 \\
24 \\
37\end{array}$ & $\begin{array}{l}\text { Normal } \\
\text { OHTN } \\
\text { POAG } \\
\text { NTG } \\
\text { Other }\end{array}$ & DOPP $<68 \mathrm{mmHg}$ & Higher risk of OAG \\
\hline Proyecto VER $(2001)^{39}$ & $\begin{array}{l}4774 \\
94\end{array}$ & $\begin{array}{l}\text { Normal } \\
\text { OAG }\end{array}$ & $\mathrm{DOPP}<50 \mathrm{mmHg}$ & 4 times higher risk of OAG \\
\hline Singapore Malay Eye Study $(2010)^{41}$ & $\begin{array}{l}3130 \\
150\end{array}$ & $\begin{array}{l}\text { No Glaucoma } \\
\text { Glaucoma }\end{array}$ & $\begin{array}{l}\text { MOPP }<46 \mathrm{mmHg} \\
\text { DOPP }<54 \mathrm{mmHg}\end{array}$ & Higher risk of OAG \\
\hline Choi et al. $(2007)^{42}$ & 113 & NTG & $\begin{array}{l}\text { Mean BP and MOPP associated } \\
\text { with thinning of RNFL }\end{array}$ & MOPP is a risk factor for NTG \\
\hline
\end{tabular}

Note: All studies used the same formulae, except for study by Choi et al. ${ }^{42}: \mathrm{MBP}=\mathrm{DBP}+[1 / 3(\mathrm{SBP}-\mathrm{DBP})] ; \mathrm{MOPP}=2 / 3(\mathrm{MBP}-\mathrm{IOP})$.

OPP, ocular perfusion pressure; OAG, Open-Angle Glaucoma; POAG, Primary Open-Angle Glaucoma; OHTN, Ocular Hypertension; NTG, Normal-Tension Glaucoma; MOPP, mean OPP; DOPP, diastolic OPP; SOPP, systolic OPP; BP, blood pressure; DBP, diastolic blood pressure; SBP, systolic blood pressure; RNFL, retinal nerve fibre layer. 


\section{Ocular blood flow, OPP and retinal associations}

The OBF is the driving force for OPP, and thus a primary pathogenetic step in OBF instability, leading to RGC loss and serving as a premise for this discussion. ${ }^{2,45}$ Vascular factors and the instability of blood flow are predictors of progression. ${ }^{2}$ Besides this, optic disc haemorrhage, migraine and obstructive sleep apnoea syndrome (OSAS) have also been found to been predictive factors for glaucoma progression. The risk for, and progression of, both POAG and/or NTG increases with the influence of OPP.

Migraines are known as vasospastic disorders and have been associated with NTG. The Low-Pressure Glaucoma Treatment Study ${ }^{46}$ reported migraines as a predicting factor for optic disc haemorrhage in NTG cases. Trivli et al. ${ }^{2}$ found that $65 \%$ of patients with NTG with systemic hypotension also presented with vasospasm. This could highlight the additional role of vascular dysregulation. Subgroups related with vascular dysregulation include those on multiple systemic anti-hypertensive medication, patients with orthostasis, systemic nocturnal hypotension, vascular disease and endothelial dysfunction. A common characteristic of dysregulation under these conditions is a disruption in the vascular mechanism, occurring either primarily or secondary to other changes, which can interfere with autoregulation and increase ONH susceptibility to vascular changes. ${ }^{47}$

The pattern electroretinogram (PERG) has been established as a sensitive indicator of the inner retinal dysfunction induced by acute or chronic ischemia in vascular occlusive diseases. Experimental studies in humans, using the PERG, showed that a decrease in RGC function was proportional to the decrease in OPP. ${ }^{48}$ Bowd et al. ${ }^{49}$ suggested that the PERG amplitude is significantly associated with macular GCC thickness, RNFL thickness and macular thickness, and is primarily driven by RGC responses. Animal studies ${ }^{50}$ recorded ganglion cells' action potentials and tested the sensitivity of the RNFL at varying BP and IOP levels and found that the ganglion cell axon electrical function was dependent on OPP and not on the absolute IOP. Other animal studies $^{51}$ also altered OPP by maintaining IOP and lowering $\mathrm{BP}$ levels, and determined the electrical activity of the ganglion cells using the PERG and flash electroretinogram (FERG). The study showed that the ERG amplitude responses are impaired as the OPP decreases and disappears when OPP reaches a critical value. This indicates that the impairment of the retinal blood supply may be responsible for the disappearance of the retinal electrical activity during OPP alteration. Furthermore, the RGCs appear less likely to recover from the acute ischemic episode.

Ocular blood flow reduction or instability, resulting in a decrease in OPP, is an important factor associated with glaucoma progression. Hypotension, migraines and OSAS all have common factors, which ultimately may lead to the disruption of RGC function and subsequently retinal thinning.

\section{The role of GCC and RNFL thickness in retinal perfusion The utility of GCC and RNFL evaluation in
glaucoma}

The GCC is made up of the RNFL, the ganglion cell layer (GCL) and the inner plexiform layer (IPL). ${ }^{52}$ The IPL is made up of the ganglion cell dendrites, the GCL consists of the ganglion cell bodies and the RNFL is made up of the ganglion cell axons..$^{53}$ Because the GCC is made up of axons, cell bodies and dendrites of the GCL, it can assist in early glaucoma detection. ${ }^{52} \mathrm{~A}$ decrease in macular thickness is because of thinning of the GCL and has been documented in glaucoma subjects. ${ }^{54}$

Retinal ganglion cells have been found to be particularly sensitive to acute, transient and mild systemic hypoxic stress. ${ }^{55}$ Results from a study by Bhagat et al. ${ }^{53}$ showed that GCC analysis may find progression at an early stage analysis in pre-perimetric glaucoma. Similarly, Coscas et al. ${ }^{56}$ found that GCC analysis is particularly useful in pre-perimetric glaucoma. Because RGCs are affected in early glaucoma, it is relevant to assess the integrity of the GCC.

It has been found in glaucoma participants that progressive RGC death leads to ONH degeneration and ultimately vision loss. ${ }^{57}$ Different areas can be assessed to detect changes in the ganglion cells and these include assessing $\mathrm{ONH}$ damage, change in ganglion cell function and visual field defects. ${ }^{58}$ Approximately $50 \%$ of total ganglion cells synapse in the central $5 \mathrm{~mm}$ of the macula and the average GCC thickness is approximately 95 microns to 100 microns, depending on the ocular coherence tomographer (OCT) used. ${ }^{58}$

Harwerth et al..$^{59}$ found that there was difficulty in detecting changes at an early stage of glaucoma, as $40 \%$ of ganglion cells need to be lost before a visual field defect becomes manifested. Similar results were found by KerriganBaumrind et al., ${ }^{60}$ showing that the relationship between sensitivity and neural loss is systematic only after $50 \%$ of ganglion cells have died. In another study by Harwerth et al., ${ }^{61}$ it was found that significant visual field abnormalities occur only after $25 \%-35 \%$ of ganglion cells are lost. Changes in the $\mathrm{ONH}$ are slow in glaucoma, therefore making detecting structural changes difficult as there needs to be a significant loss of rim tissue. ${ }^{58}$ This further indicates the importance of assessing the integrity of RGCs in early glaucoma, or in people who may be at risk of glaucomatous changes.

Thinning of the GCC may precede RNFL loss in some patients and GCC analysis provides information regarding the inner macular area. The optic nerve consists of RGC axons, and the superior and inferior parts of the optic nerve consist of retinal nerve fibres which originate from the temporal and nasal hemi-retinal areas. The GCC temporal to the fovea in the temporal hemi-retinal area consists only of RGCs that reside within corresponding areas. The GCC may 
be superior to the circumpapillary RNFL since there is an enrichment of RGCs combined with retinotopic segregation. ${ }^{62}$

Ganglion cell complex analysis has been compared to RNFL analysis using the special domain ocular coherence tomographer (SD-OCT), and it has been found that the two areas on the fundus have comparable diagnostic accuracy for glaucoma. ${ }^{63}$ In a study by Kim et al., ${ }^{64}$ it was found that macular GCC thickness was comparable to RNFL thickness in early, moderate and severe glaucoma. Seong et al. ${ }^{17}$ found that, in NTG sufferers, the average macular GCC thickness showed a strong correlation with peri-papillary RNFL thickness and is useful in the detection of glaucoma.

Analysis of GCC and RNFL thickness has proven to be significant in the event of lowered OPP, as an indication of early retinal or glaucomatous changes. There is a lack of studies aimed at measuring systemic hypotension and its effect on RNFL thickness. However, the Los Angeles Eye Study ${ }^{18}$ found that low DOPP, SOPP and MOPP, low DBP, high SBP and a high mean $\mathrm{BP}$ are associated with a higher prevalence of OAG in adult Latinos, indicating a 'U-shaped' curve. The higher and lower ends or the extremes of the curve are most susceptible to changes in OPP or vascular dysregulation.

\section{The utility of GCC and RNFL evaluation in non- glaucomatous conditions with reduced blood flow}

A study by Kergoat et al. ${ }^{55}$ of induced hypoxic conditions in humans found that RGCs are sensitive to mild systemic hypoxic stress. Furthermore, the study found that the innermost layers of the retina are more sensitive to low-level systemic hypoxia compared to the outermost layers. Therefore, evaluating the innermost layers of the retina, such as the GCC and RNFL, as a result of hypoxic changes because of reduced OPP, is valuable. Table 3 shows studies that indicate changes in the retina related to reduced OPP in conditions with reduced blood flow. This includes healthy people, those with Obstructive Sleep Apnea Syndrome (OSAS) and systemic hypertension.

Obstructive sleep apnoea syndrome is characterised by obstruction in the upper airway resulting in episodes of hypoxia. Studies measuring RNFL thickness in OSAS have found a positive correlation between RNFL thinning and OSAS. Low oxygen saturation has been significantly

TABLE 3: Studies showing retinal changes from reduced retinal perfusion.

\begin{tabular}{|c|c|c|c|}
\hline Study (year) & $n$ & $\begin{array}{l}\text { Conditions } \\
\text { susceptible to OPP }\end{array}$ & RNFL association \\
\hline Kergoat et al. (2006) ${ }^{55}$ & 20 & Healthy people & $\begin{array}{l}\text { RGC sensitive to mild } \\
\text { hypoxia }\end{array}$ \\
\hline Kargi et al. (2005) & 34 & OSAS & $\begin{array}{l}\text { RNFL thinning } \\
\text { proportionate to the } \\
\text { severity }\end{array}$ \\
\hline Hashim et al. (2014) 68 & 39 & OSAS & $\begin{array}{l}\text { RNFL thinning in severe } \\
\text { OSAS }\end{array}$ \\
\hline Zengin et al. (2014) 67 & 44 & OSAS & RNFL thinning in OSAS \\
\hline Gangwani et al. $(2015)^{69}$ & 4000 & $\begin{array}{l}\text { Systemic } \\
\text { hypertension }\end{array}$ & $\begin{array}{l}\text { High SBP, DBP and MOPP } \\
\text { associated with thinning } \\
\text { RNFL }\end{array}$ \\
\hline
\end{tabular}

OPP, ocular perfusion pressure; OSAS, Obstructive sleep apnoea syndrome; RNFL, retinal nerve fibre layer; SBP, systolic blood pressure; DBP, diastolic blood pressure; MOPP, mean ocular perfusion pressure; RGC, retinal ganglion cells. associated with thinning of the RNFL, ONH changes and macular thickness. The mechanism supporting RNFL thinning in OSAS is associated with several vascular disturbances. When coupled with nocturnal hypotension, this exacerbates the damage and thinning of the RNFL. ${ }^{65}$

Kargi et al. ${ }^{66}$ determined RNFL thickness in OSAS patients using a scanning laser polarimeter and found that thinning of RNFL was proportional to the severity of the disease. The study speculated that profound hypoxia and vascular dysregulation in OSAS may be the cause of RNFL thinning by disturbing OPP. The thinning of the RNFL may be caused by the loss of ganglion cells secondary to hypoxia, as well as hypoxemia induced by OSAS.

Zengin et al. ${ }^{67}$ tracked RNFL thickness measurements over a year in OSAS patients and showed a reduction in RNFL thickness between the first and last measurements. Further to this, Hashim et al. ${ }^{68}$ studied the prevalence of glaucoma in patients with OSAS by measuring RNFL thickness using an OCT. The study found that $87.5 \%$ of participants with severe OSAS had glaucoma and concluded that the alteration in OBF in OSA may have resulted in glaucoma. These results suggest that individuals with conditions such as OSAS, which affect retinal blood flow and ocular perfusion, may be susceptible to glaucomatous optic neuropathy.

Gangwani et al. ${ }^{69}$ measured RNFL thickness in patients with systemic hypertension to determine any association between RNFL thickness and SBP, DBP and MAP in patients with medically treated systemic hypertension. Patients with systemic hypertension on anti-hypertensive medication are at risk of progressive RNFL thinning and glaucoma. Higher SBP, DBP and mean arterial perfusion pressure (MAPP) were associated with thinner RNFL thickness, and $1.3 \%$ of them were confirmed with NTG, which is in agreement with the Los Angeles Latino Eye Study, ${ }_{18}^{18}$ which reported a higher prevalence of POAG with higher SBP and MAP. Over-treating hypertension exacerbates glaucoma, as excessively lowering BP in glaucoma patients may cause a drop in OPP and subsequent ischemic injury, ${ }^{70}$ suggesting that treatment-induced systemic hypotension may influence progressive retinal changes for at-risk populations.

Another condition, diabetes mellitus also causes vascular and RNFL changes in the presence of retinopathy and these changes can occur in the absence of glaucoma and other optic nerve diseases. ${ }^{71}$ Alteration in metabolic pathways in diabetics can affect the functioning and loss of retinal cells, ganglion cells, bipolar and photoreceptors. ${ }^{72}$ Dhasmana et al. ${ }^{71}$ studied RNFL thickness in diabetics and found significant thinning in both the RNFL and GCC. The study concluded that neurodegeneration is a significant component in the early stages of diabetic retinopathy. ${ }^{71}$ El-Hifnawy et al. $^{73}$ studied RNFL in diabetics without retinopathy or macular oedema and also found thinning of RNFL, suggesting that early retinal neurodegeneration can occur before vascular changes are observed. Thus, a similar mechanism for changes in retinal hypoxia and ganglion cell function, resulting in inner retinal dysfunction, is displayed in diabetics, strengthening the case 
for reduced perfusion and blood flow and retinal effects; and this may also help make a case for systemic hypotension and possible retinal involvement.

\section{Systemic hypotension and ocular perfusion concerns}

Hypotension generally goes undiagnosed unless the patient presents with symptoms. Systemic hypotensive has been found to have relatively low sympathetic nerve activity leading to low SBP, along with lower BMI and body temperature. ${ }^{36}$ Chronic constitutional hypotension has been known to affect quality of life. Symptoms that present in systemic hypotensive include headaches, dizziness, fatigue, loss of concentration and feeling faint. As there is no clinical diagnosis for hypotension, we have used SBP $<100 \mathrm{mmHg}$ (WHO) to presume hypotension.

Cardiologists do not recognise low BP as a risk. However, some individuals with chronic systemic hypotension may be at risk of damage to end organs including the eye. ${ }^{3,45}$ A greater incidence of progression has been found in patients with low $\mathrm{BP}$ and lower IOP, suggesting a significant vascular risk independent of IOP. ${ }^{45}$ The Early Manifest Glaucoma Trial ${ }^{38}$ showed that cardiovascular risk factors have a significant effect on long-term progression of the disease. The study found that patients with SBP less than $60 \mathrm{mmHg}$ and with IOP less than $21 \mathrm{mmHg}$ were at a higher risk of progression.

Intraocular pressure is important to maintain the structure and physiology of the eye and is subject to circadian rhythms. ${ }^{6}$ Both IOP and BP vary throughout the day, making OPP a dynamic factor. The IOP and BP have been found to peak in the morning (9:00-10:00 am), with a trough in the afternoon (15:00-16:00 pm). ${ }^{7}$ Low OPP can occur as a result of low BP (SBP $<100 \mathrm{mmHg})$, with normal IOP $(<21 \mathrm{mmHg}) .^{2}$ The OPP has proven to be a risk factor for glaucoma and studies ${ }^{18,37}$ have found that both low BP and low OPP increase this risk. The Los Angeles Latino Eye Study ${ }^{18}$ and the Barbados Eye Study ${ }^{37}$ have found that lower MOPP, DOPP and SOPP, DBP and mean $\mathrm{BP}$ values have been shown to increase the risk of OAG by up to four times. This reduction in OPP as a result of low $\mathrm{BP}$ results in a decrease in $\mathrm{OBF}$, resulting in hypoxia to the ONH. ${ }^{3}$ Hypoxia consequently results in a loss of RGCs. Studies $^{48,50,51}$ on the effect of lowered OPP on RGC function have found that lowered BP and lowered OPP had a significant effect on GCC function. Analysis of the GCC may find glaucoma progression at an early stage ${ }^{53}$ Furthermore, the GCC and RNFL are part of the innermost layers of the retina and are more sensitive to low-level systemic hypoxia. ${ }^{55}$ This makes it relevant to assess these layers in response to hypoxic changes as a result of reduced OPP.

Figure 1 summarises the process of reduced ocular perfusion from reduced BP in systemic hypotension.

\section{Limitations}

Possible limitations that may influence the validity of diagnosis include the possibility of 'white coat syndrome'

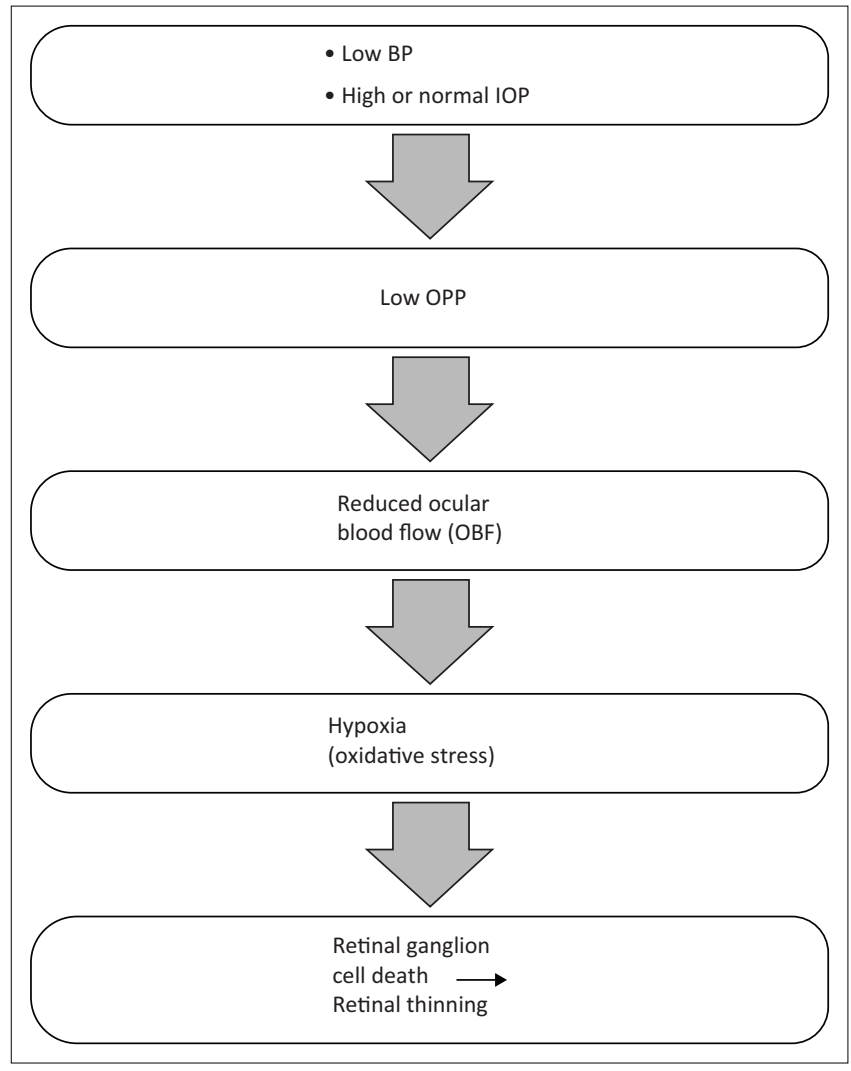

$\mathrm{BP}$, blood pressure; IOP, intraocular pressure; OPP, ocular perfusion pressure. FIGURE 1: The process of reduced ocular perfusion in systemic hypotension.

when BP measurements are obtained by clinicians in office. This suggests that readings may not be accurate because of the stress on participants when their BP is taken in the office; and systemic hypotensive sufferers may present with false normal measurements. A single measurement on each arm may not clinically account for circadian fluctuations in BP, making 24-h monitoring more relevant for hypotension, and in order to ensure an accurate diagnosis of BP. Recommendations include 24-h IOP measurements, which will provide better insight into the circadian rhythms of IOP, although this may be impractical. Factoring in characteristics such as weight and height may aid in recognising sufferers of systemic hypotension. The electroretinogram (ERG) testing may be an important indicator in determining global retinal function and may offer more precise results on the effects of OPP on retinal function.

\section{Conclusion}

The purpose of this review was to explore the relationship between systemic hypotension and OPP, and subsequently the effect of low OPP on the GCC as a risk factor for glaucoma. There is a paucity of literature on the effect of systemic hypotension on OPP and retinal thickness. However, as intimated in this review, via indirect associations with conditions that affect blood flow to the optic nerve, a case can be made for systemic hypotension and reduced retinal perfusion. The increased risk for glaucoma related with decreased BP and OPP has proven that both factors are relevant as indicators for the 
development of glaucoma. As the earliest signs of glaucoma are detected in the RNFL and GCC, it is thus valuable to assess these retinal layers. The inclusion of routine evaluation of BP and noting OPP in people with systemic hypotension during routine eye examinations may be of value. The effect of low OPP as a result of hypotension on the GCC may also help inform us whether nonglaucomatous, glaucoma suspects or glaucoma-diagnosed sufferers are at a higher risk of progressive optic neuropathy. Thus, closer monitoring of systemic hypotension sufferers may prove to be a convenient, affordable and non-invasive method of flagging decreased OPP when coupled with the evaluation of macula and ONH RNFL and GCC thickness. This may help alert clinicians to alter management in this vulnerable population.

\section{Acknowledgements Competing interests}

The authors declare that they have no financial or personal relationships that may have inappropriately influenced them in writing this article.

\section{Authors' contributions}

N.V. was the principal investigator and was responsible for construction of the manuscript. A.J.M. was the project supervisor and was responsible for review and editing of the manuscript.

\section{Ethical considerations}

Approved by the University of KwaZulu-Natal Biomedical Research Ethics Committee (BREC) (BE401/17).

\section{Funding information}

This research received no specific grant from any funding agency in the public, commercial or not-for-profit sectors.

\section{Data availability}

Data sharing is not applicable to this article.

\section{Disclaimer}

The views and opinions expressed in this article are those of the authors and do not necessarily reflect the official policy or position of any affiliated agency of the authors.

\section{References}

1. Wang L, Cull GA, Fortune B. Optic nerve head blood flow response to reduced ocular perfusion pressure by alteration of either the blood pressure or intraocular pressure. Curr Eye Res. 2015;40(4):359-367. https://doi.org/10.3109/02713683. 2014.924146

2. Trivli A, Koliarakis I, Terzidou C, et al. Normal-tension glaucoma: Pathogenesis and genetics (review). Exp Ther Med. 2019;17(1):563-574. https://doi.org/10.3892/ etm.2018.7011

3. Karmel M. The new pressure for glaucoma specialists: Ocular perfusion arrive [homepage on the Internet]. American Academy of Ophthalmology; 2011 [cited $2021 \mathrm{Apr} 29]$. Available from: http://www.aao.org/eyenet/article/new-pressureglaucoma-specialists-ocular-perfusion
4. Flammer J, Orgül S, Costa VP, et al. The impact of ocular blood flow in glaucoma. Prog Retin Eye Res. 2002;21(4):359-393. https://doi.org/10.1016/S13509462(02)00008-3

5. Fogagnolo P, Orzalesi N, Ferreras A, et al. The circadian curve of intraocular pressure: Can we estimate its characteristics during office hours? Invest Ophthalmol Vis Sci. 2009;50(5):2209-2215. https://doi.org/10.1167/iovs.08-2889

6. David R, Zangwill L, Briscoe $D$, et al. Diurnal intraocular pressure variations: An analysis of 690 diurnal curves. Br J Ophthalmol. 1992;76(5):280-283. https://doi. org/10.1136/bjo.76.5.280

7. Sajja S, Vemapti P. Diurnal variation of intra ocular pressure (IOP) in healthy individuals: A pilot study. Sch J Appl Med Sci. 2013;1(5):488-492.

8. Dinn RB, Zimmerman MB, Shuba LM, et al. Concordance of diurnal intraocular pressure between fellow eyes in primary open-angle glaucoma. Ophthalmology. 2007;114(5):915-920.

9. Shuba LM, Doan AP, Maley MK, et al. Diurnal fluctuation and concordance of intraocular pressure in glaucoma suspects and normal tension glaucoma patients. Glaucoma. 2007;16(3):307-312. https://doi.org/10.1097/IJG.0b013e3180316736

10. Bhorade AM, Gordon MO, Wilson B, et al. Variability of intraocular pressure measurements in observation participants in the ocular hypertension treatment study. Ophthalmology. 2009;116(4):717-724. https://doi. org/10.1016/j.ophtha.2008.12.036

11. Kim Y-K, Hyuk Oh W, Ho Park K, et al. Circadian blood pressure and intraocular pressure patterns in normal tension glaucoma patients with undisturbed sleep. pressure patterns in normal tension glaucoma patients with undisturbed sleep.
Korean J Ophthalmol. 2010;24(1):23-28. https://doi.org/10.3341/kjo.2010.24.1.23

12. Liu JHK, Gokhale PA, Loving RT, et al. Laboratory assessment of diurnal and nocturnal ocular perfusion pressures in humans. J Ocul Pharmacol Ther. 2003;19(4):291-297. https://doi.org/10.1089/108076803322279354

13. Kotecha A, Crabb DP, Spratt A, et al. The relationship between diurnal variations in intraocular pressure measurements and central corneal thickness and corneal hysteresis. Invest Ophthalmol Vis Sci. 2009;50(9):4229-4236.

14. Kim MS, Kim JM, Park KH, et al. Asymmetry of diurnal intraocular pressure fluctuation between right and left eyes. Acta Ophthalmol. 2011;89(4):352-357. https://doi.org/10.1111/j.1755-3768.2009.01672.x

15. Buddle R. A day in the life of IOP. Rev Optom [serial online]. 2014 [cited 2020 Nov 09] Available from: https://www.reviewofoptometry.com/article/a-day-in-the-life-of-iop

16. He Z, Vingrys A, Armitage J, et al. The role of blood pressure in glaucoma. Clin Exp Optom. 2011;94(2):133-149.

17. Seong $M$, Sung $K R$, Choi $E H$, et al. Macular and peripapillary retinal nerve fiber layer measurements by spectral domain optical coherence tomography in normaltension glaucoma. Invest Ophthalmol Vis Sci. 2010;51(3):1446. https://doi. org/10.1167/iovs.09-4258

18. Memarzadeh F, Ying-Lai $M$, Chung J, et al. Blood pressure, perfusion pressure, and open-angle glaucoma: The Los Angeles Latino Eye Study. Invest Ophthalmol Vis Sci. 2010;51(6):2872-2877

19. Tielsch JM, Katz J, Sommer A, et al. Hypertension, perfusion pressure, and primary open-angle glaucoma. Arch Ophthalmol. 1995;113(2):216-221. https://doi. org/10.1001/archopht.1995.01100020100038

20. Weinreb RN, Aung T, Medeiros FA. The pathophysiology and treatment of glaucoma: A review. JAMA. 2014;311(18):1901-1911. https://doi.org/10.1001/ jama.2014.3192

21. Mancia G, Fagard R, Narkiewicz K, et al. 2013 ESH/ESC Guidelines for the management of arterial hypertension. Eur Heart J. 2013;34(28):2159-2219. https://doi.org/10.1093/eurheartj/eht151

22. WHO Expert Committee. Arterial hypertension. Technical Series Report 628. Geneva: World Health Organisation, 1978; p. 7-58.

23. Mutschler E, Hartmut D. Drug actions: Basic principles and therapeutic aspects. Stuttgart: Medpharm Scientific Publishers, 1995; 389 p.

24. Duschek S, Schandry R. Reduced brain perfusion and cognitive performance due to constitutional hypotension. Clin Auton Res Soc. 2007;17(2):69-76. https://doi org/10.1007/s10286-006-0379-7

25. Center for Health Statistics N. Vital and health statistics [homepage on the Internet]. Series 10, Number 259. 2012 [cited 2020 Nov 9]. Available from: https://www.cdc.gov/nchs/data/series/sr_10/sr10_259.pdf

26. Barrett-Connor E, Palinkas L. Low blood pressure and depression in older men: A population based study. BMJ. 1994;308:446-449. https://doi.org/10.1136/ bmj.308.6926.446

27. Pilgrim JA, Stansfeld S, Marmot M. Low blood pressure, low mood? BMJ. 1992;304:75-78. https://doi.org/10.1136/bmj.304.6819.75

28. Rosengren A, Tibblin G, Wilhelmsen L. Low systolic blood pressure and selfperceived well-being in middle aged men. BMJ. 1993;306:243-246. https://doi org $/ 10.1136 / \mathrm{bmj} .306 .6872 .243$

29. Owens P, Lyons S, O 'Brien E. Arterial hypotension: Prevalence of low blood pressure in the general population using ambulatory blood pressure monitoring. Hum Hypertens. 2000;14(14):243-247.

30. Degaute JP, Van de Borne P, Linkowski P, et al. Quantitative analysis of the 24-hour blood pressure and heart rate patterns in young men. Hypertension. 1991;18(2):199-210. https://doi.org/10.1161/01.HYP.18.2.199

31. Koroboki E, Manios E, PsaltoPoulou T, et al. Circadian variation of blood pressure and heart rate in normotensives, white-coat, masked, treated and untreated hypertensives. Hellenic J Cardiol. 2012;53(6):432-438.

32. Handler J. The importance of accurate blood pressure measurement. Perm J. 2009;13(3):51-54. https://doi.org/10.7812/TPP/09-054

33. Pickering TG, Hall JE, Appel LJ, et al. Recommendations for blood pressure measurement in humans and experimental animals. Circulation. 2005;111(5):697-716. 
34. Wessely S, Nickson J, Cox B. Symptoms of low blood pressure: A population study. BMJ. 1990;301:362-365. https://doi.org/10.1136/bmj.301.6748.362

35. Pemberton J. Does constitutional hypotension exist? BMJ. 1989;298:660-662.

36. Akahoshi M, Hida A, Imaizumi M, et al. Basic characteristics of chronic hypotension cases: A longitudinal follow-up study from 1958 through 1999. Hypertens Res. 2006;29(1):1-7

37. Leske MC, Wu S-Y, Nemesure B, et al. Incident open-angle glaucoma and blood pressure. Arch Ophthalmol. 2002;120(7):954-959. https://doi.org/10.1001/ archopht.120.7.954

38. Leske MC, Heijl A, Hyman L, et al. Early manifest glaucoma trial. Ophthalmology. 1999;106(11):2144-2153. https://doi.org/10.1016/S0161-6420(99)90497-9

39. Quigley HA, West SK, Rodriguez J, et al. The prevalence of glaucoma in a population-based study of Hispanic subjects. Arch Ophthalmol. 2001;119(12):1819.

40. Bonomi L, Marchini G, Marraffa M, et al. Vascular risk factors for primary open angle glaucoma: The Egna-Neumarkt Study. Ophthalmology. 2000;107(7):1287-1293. https://doi.org/10.1016/S0161-6420(00)00138-X

41. Zheng $Y$, Wong TY, Mitchell $P$, et al. Distribution of ocular perfusion pressure and its relationship with open-angle glaucoma: The Singapore Malay Eye Study. Invest Ophthalmol Vis Sci. 2010;51(7):3399. https://doi.org/10.1167/iovs.09-4867

42. Choi J, Kim KH, Jeong J, et al. Circadian fluctuation of mean ocular perfusion pressure is a consistent risk factor for normal-tension glaucoma. Invest Ophthalmol Vis Sci. 2007;48(1):104.

43. Cherecheanu AP, Garhofer G, Schmidl D, et al. Ocular perfusion pressure and ocular blood flow in glaucoma. Curr Opin Pharmacol. 2013;13(1):36-42. https:// doi.org/10.1016/j.coph.2012.09.003

44. Choi J, Kook MS. Systemic and ocular hemodynamic risk factors in glaucoma. Biomed Res Int. 2015;2015:1-9.

45. Caprioli J, Coleman AL. Blood pressure, perfusion pressure, and glaucoma. Am Ophthalmol. 2010;149(5):704-712. https://doi.org/10.1016/j.ajo.2010.01.018

46. Furlanetto RL, De Moraes CG, Teng CC, et al. Risk factors for optic disc hemorrhage in the low-pressure glaucoma treatment study. Am J Ophthalmol. 2014;157(5):945-952. https://doi.org/10.1016/j.ajo.2014.02.009

47. Moore D, Harris A, Wudunn D, et al. Dysfunctional regulation of ocular blood flow: A risk factor for glaucoma? Clin Ophthalmol. 2008;2(4):849-861. https://doi. org/10.2147/OPTH.S2774

48. Colotto A, Falsini B, Salgarello T, et al. Transiently raised intraocular pressure reveals pattern electroretinogram losses in ocular hypertension. Invest Ophthalmol Vis Sci. 1996;37(19):2663-2670.

49. Bowd C, Tafreshi A, Zangwill LM, et al. Pattern electroretinogram association with spectral domain-OCT structural measurements in glaucoma. Eye. 2011;25(2):224-232. https://doi.org/10.1038/eye.2010.203

50. Grehn F, Prost M. Function of retinal nerve fibers depends on perfusion pressure: Neurophysiologic investigations during acute intraocular pressure elevation. Invest Ophthalmol Vis Sci. 1983;24(3):347-353.

51. Siliprandi R, Bucci MG, Canella R, et al. Flash and pattern electroretinograms during and after acute intraocular pressure elevation in cats. Invest Ophthalmo Vis Sci. 1988;29(4):558-565.

52. Bruce A, Huang I. What is the earliest test for glaucoma? Pharma. 2014;8:9.

53. Raj Bhagat $P$, Vivek Deshpande K, Natu B. Utility of ganglion cell complex analysis in early diagnosis and monitoring of glaucoma using a different spectral domain
optical coherence tomography. J Curr Glaucoma Pract. 2014;88(33):101-106. optical coherence tomography. J Curr Glaucom
https://doi.org/10.5005/jp-journals-10008-1171

54. Cheema A. Spectral domain optical coherence tomography in glaucoma [homepage on the Internet. American Academy of Ophthalmology. EyeWiki; 2015 [cited 2021 Jun 08]. Available from: http://eyewiki.aao.org/Spectral_Domain Optical_Coherence_Tomography_in_Glaucoma
55. Kergoat $H$, He'rard M-E, Lemay M. RGC sensitivity to mild systemic hypoxia. Invest Ophthalmol Vis Sci. 2006;47(12):5423-5427. https://doi.org/10.1167/iovs.06-0602

56. Coscas G, Loewenstein A, Bandello F. Optical coherence tomography. Switzerland: Karger; 2014.

57. Kuehn $\mathrm{MH}$, Fingert JH, Kwon YH. Retinal ganglion cell death in glaucoma: Mechanisms and neuroprotective strategies. Opthalmol Clin N Am. 2005;18:383-395. https://doi.org/10.1016/j.ohc.2005.04.002

58. Lakkis G. The ganglion cell complex and glaucoma. Pharma J Glaucoma. 2013;28-32.

59. Harwerth RS, Quigley HA. Visual field defects and retinal ganglion cell losses in patients with glaucoma. Arch Ophthalmol. 2006;124(6):853-859. https://doi. org/10.1001/archopht.124.6.853

60. Kerrigan-Baumrind LA, Quigley HA, Pease ME, et al. Number of ganglion cells in glaucoma eyes compared with threshold visual field tests in the same persons. Invest Ophthalmol Vis Sci. 2000;41(3):135-748.

61. Harwerth RS, Carter-Dawson L, Shen F, et al. Ganglion cell losses underlying visual field defects from experimental glaucoma. Invest Ophthalmol Vis Sci. 1999;40(10):186-2250.

62. Salazar JJ, Ramírez Al, De Hoz R, et al. Anatomy of the human optic nerve: Structure and function. Spain: IntechOpen, 2018; p. 11-56.

63. Anguelov B, Petrova K. Diagnostic accuracy of the parameters from ganglion cell complex map, evaluated with SD-OCT in primary open-angle glaucoma. Ophthalmol Russia. 2014;11(3):28-32.

64. Kim NR, Lee ES, Seong GJ, et al. Structure-function relationship and diagnostic value of macular ganglion cell complex measurement using fourier-domain oct in glaucoma. Invest Ophthalmol Vis Sci. 2010;51(9):4646. https://doi.org/10.1167/iovs.09-5053

65. Chaitanya A, Pai V, Mohapatra A, et al. Glaucoma and its association with obstructive sleep apnea: A narrative review. Oman J Ophthalmol. 2016;9:125. https://doi.org/10.4103/0974-620X.192261

66. Kargi S, Altin R, Koksal M, et al. Retinal nerve fibre layer measurements are reduced in patients with obstructive sleep apnoea syndrome. Eye. 2005;19:575-579. https://doi.org/10.1038/sj.eye.6701582

67. Zengin MO, Tuncer I, Karahan E. Retinal nerve fiber layer thickness changes in obstructive sleep apnea syndrome: One year follow-up results. Inter J Ophthalmol. 2014;7(4):704-708.

68. Hashim SP, Al Mansouri F, Farouk M, et al. Prevalence of glaucoma in patients with moderate to severe obstructive sleep apnoea: Ocular morbidity and outcomes in a 3-year follow-up study. Eye. 2014;28(11):1304-1309. https://doi.org/10.1038/ eye.2014.195

69. Gangwani RA, Lee JWY, Mo HY, et al. The correlation of retinal nerve fiber layer thickness with blood pressure in a Chinese hypertensive population. Medicine. 2015;94(23):947. https://doi.org/10.1097/MD.0000000000000947

70. Chung HJ, Hwang H Bin, Lee NY. The association between primary open-angle glaucoma and blood pressure: Two aspects of hypertension and hypotension. Biomed Res Int. 2015;2015:1-7. https://doi.org/10.1155/2015/827516

71. Dhasmana R, Sah S, Gupta N. Study of retinal nerve fibre layer thickness in patients with diabetes mellitus using fourier domain optical coherence tomography. J Clin Diag Res. 2016;10(7):5-9. https://doi.org/10.7860/ JCDR/2016/19097.8107

72. Ly A, Yee P, Vessey KA, et al. Early Inner retinal astrocyte dysfunction during diabetes and development of hypoxia, retinal stress, and neuronal functional loss. Invest Ophthalmol Vis Sci. 2011;2011(52):9316-9326. https://doi.org/10.1167/ iovs.11-7879

73. El-Hifnawy M, Sabry K, Gomaa A, et al. Effect of diabetic retinopathy on retinal nerve fiber layer thickness. Delta J Ophthalmol. 2016;17(3):162. https://doi. org/10.4103/1110-9173.195262 